\title{
Obrar mal, decir la verdad. La función de la confesión en la justicia. Curso de Lovain Michel Foucault
}

Siglo XXI Editores, Buenos Aires, Argentina, 2014, 368 págs.

Mario Ociel Moya

Programa de Doctorado en Antropología, Instituto de Investigaciones Arqueológicas y Museo R.P. Gustavo Le Paige S.J. Universidad Católica del Norte. San Pedro de Atacama, Chile. Becario CONICYT.

Email: mmoya@ucn.cl

¿Qué llevó a Robert-François Damiens a ser condenado y supliciado hasta la muerte? Primero, la existencia un acto ilegal cometido por el condenado, el intento de asesinato contra Luis XV -el obrar mal-; Segundo, el conocimiento de la acción -la verdad-por unos otros. Aunque en el caso de Damiens, la verdad nunca fue admitida ni confesada por el acusado, surtió de los mismos efectos que si la confesión se hubiese materializado: el conocimiento de un hecho como verdad (el ilícito), la individualización del culpable (Damiens) y el castigo (hacer morir por medio del suplicio). Me atrevo a tomar el caso de Damiens descrito en la primera parte de Vigilar y castigar por Foucault (2000), para explicar de mejor manera la problemática del este curso, en donde la confesión, la verdad y los usos ella, constituyen los ejes centrales en Obrar mal, decir la verdad (Foucault 2014).

La verdad fue para Foucault un eje rector para sus reflexiones, ya sea, la verdad en los enunciados y prácticas cristianas, en sus formas jurídicas y políticas o en el orden de lo científico y lo médico graficado, particularmente, por la práctica clínica sobre la conciencia (por ejemplo, mediante el psicoanálisis) o sobre los cuerpos y las voluntades (mediante la práctica médica). Como sea, en el devenir de las instituciones occidentales y la relación asimétricas con los sujetos y la población (indistintamente del contexto disciplinario o de control), los enunciados de verdad se conforman, según lectura foucaultiana, como regímenes que sedimenta un orden social y político específico, mediante el manejo, disciplinamiento y control de las conductas de los sujetos. No se trataría, entonces, para Foucault, del análisis de la verdad versus el error o la falsedad; de la racionalidad versus la irracionalidad o ciencia versus la ideología -problemas suficientemente trabajados por la filosofía, la epistemología, y específicamente, por la axiología-; sino que el abordaje foucaultiano de la verdad se encuentra íntimamente ligado al análisis del poder, de los dispositivos utilizados y su materialización práctica en el gobierno de los otros. 
Continuando y complementando la ya tradicional publicación de los cursos de Foucault del Collège de France, Obrar mal, decir la verdad, es un quiebre en este sentido al tratarse de la publicación de un curso dictado en la Université Catholique de Louvain (UCL, Bélgica) -en el marco de la Cátedra Franqui-, en donde, para esta primera edición, la traducción al español estuvo a cargo de Horacio Pons y revisada por el conocido investigador de la obra foucaultiana, Edgardo Castro.

Obrar mal, decir la verdad, libro dividido en cuatro partes: una conferencia inaugural, seis clases dictadas entre el 22 de abril y el 20 de mayo de 1981, dos entrevistas a Foucault realizadas en dicha estancia en Lovaina y el tradicional apéndice en la publicación de las clases de Foucault, situación del curso, vienen a presentar una historia... la historia de la confesión, artilugio que, como se presenta en este libro, ha sufrido transformaciones e innovaciones al igual que el uso de la verdad de ahí provenida, y como veremos, en ocasiones también producida mediante la idea o materialización de la tortura.

Por medio de la descripción de un diálogo entre un psiquiatra y su paciente, Foucault comienza a definir el campo de la confesión y su función como parte del proceso terapéutico; para más tarde, ampliar su análisis a la confesión en su formas cristianas y jurídicas, ejemplificando, como siempre, con aquellas problemáticas que tradicionalmente a Foucault le interesaron: la locura, la enfermedad y el crimen.

Mediante la utilización de una definición bastante general de confesión "[...] declaración escrita u oral mediante la cual uno reconoce haber dicho o hecho algo [...]” (Foucault 2014:24), Foucault sitúa el acto confesatorio en el marco de los juegos del lenguaje, juegos que en su despliegue práctico -especialmente por el uso de la confesión y la verdad por quienes ostentan el poder- tiene consecuencias, riesgos o algún costo para quien o quienes confiesan. Así, el riesgo o las consecuencias del decir veraz, se estatuye como la principal diferencia de la mera declaración. Acá un elemento paradojal cuando en rigor, nos dice Foucault, la única confesión que llega a constituirse como tal, es aquella que se hace de manera voluntaria.

Paradoja absoluta, además, cuando en el desarrollo de las clases posteriores a la conferencia inaugural, Foucault detalla y ejemplifica cómo el acto confesatorio supera su propio rol al ubicarse "en la frontera entre el procedimiento acusatorio tradicional y el [...] procedimiento inquisitorio" (Foucault 2014:221) En efecto, los procedimientos acusatorios y el uso de evidencia o pruebas (algunas como el duelo judicial o contienda entre los adversarios con verdades disímiles), comienzan a vincularse con el uso cuerpo, no solo para el castigo, sino también, el uso del cuerpo para la aplicación de técnicas de torturas -o la amenaza de aquella- para la producción de elementos de verdad operativos para dicho procedimiento inquisitorio, tal como nos muestra en el caso de Damiens (Foucault 2000). 
Pero existen otras complejidades no menores. En el mismo escenario del procedimiento inquisitorio, es importante considerar la complejidad y la importancia que tiene lo material en el procedimiento inquisitorio, particularmente, si se atiende como la materialidad excede al cuerpo. En efecto, el rastrear, el observar y buscar pruebas, es para Foucault el arte del descubrimiento, en donde mediante la utilización de "[...] signos, las huellas, las marcas, que permite remontarse de lo que no se sabe a lo que se sabe sobre la base de elementos materiales [...]" (Foucault 2014:87), como resultado de una racionalidad práctica regida por un objetivo consciente, de una techne dirigida hacia la verdad.

Queda, por otra parte, una vez más en evidencia el interés de Foucault por el mundo griego antiguo para el desarrollo y ejemplificación de sus ideas. Nos muestra a través del análisis de los Trabajos y los días de Hesíodo, de Edipo Rey de Sófocles y la Ilíada de Homero, aquellas mutaciones del decir veraz en tanto acto verbal y práctica. En el caso de la Ilíada, por ejemplo, Foucault identifica en dicho relato la incipiente materialización del decir veraz como un acto de confesión judicial en el conflicto entre Antíloco y Menelao por el triunfo de una carrera descrita en el canto XXIII. Una escena fundamentalmente judicial, nos indica Foucault, al existir la instauración de un conflicto, la búsqueda de una verdad y la resolución mediante un litigio. Existe en dicho relato un personaje investido del rol de Juez Aquiles-, y el apoyo de este a la hora de tomar una decisión en los guerreros presentes; judicial en sus formas, pero ética en el desenlace, pues los personajes del relato actúan en función de la verdad y lo justo, pues, como muestra en el final del canto XXIII, Menelao dimite del premio en conflicto.

Consecuente con la aproximación a la verdad en tanto práctica, Foucault continúa el análisis del decir veraz problematizando el cómo la verdad se manifiesta:

i) en el mundo griego -mediante el conócete a ti mismo ( $\Gamma \nu \varpi \theta t$

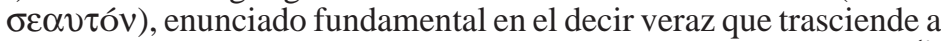

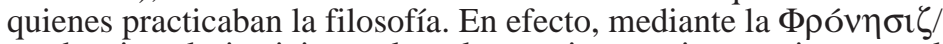
prudencia y la justicia, en la cultura griega antigua se instaura el decir veraz como un forma institucionalizada en la vida cotidiana,

ii) en el uso del decir veraz por el cristianismo antiguo y en el que, de alguna forma, podemos llamar cristianismo moderno con la figura de la confesión de los pecados o examen de conciencia (relación hombre-divinidad)

iii) en el uso la confesión por el saber médico -mediante la relación médico paciente- (confesión de los males o malestares físicos) y, finalmente,

iv) en las prácticas jurídicas para la distribución y gestión de la justicia, puesto que, lo que uno dice de sí mismo es utilizado, o al menos puede serlo, ser usado en contra de sí. 
Así, es la confesión lo que Foucault desarrolla y profundiza en los estudios presentados en Obrar mal, decir la verdad en 1981, estudios que, según entendemos, vienen a complementar los cursos posteriores en el Collège de France, a saber: El gobierno de sí y de los otros (Foucault 2009) entre 1982 y 1983; y El coraje de la verdad (2010) dictado entre los años 1983 y 1984, en donde desarrolla en extenso la noción de parrhesía (la libertad para decir las prácticas del decir veraz sobre sí mismo, el hablar franco como acto político)

En la Historia de la sexualidad. 1.- La voluntad de saber (Foucault 2002), enuncia la utilidad de la confesión como producción del discurso verídico sobre el sexo, la producción y reproducción de una de cienciaconfesión, ciencia que "[...] que se apoyaba en los rituales de la confesión y en sus contenidos, una ciencia que suponía esa extorsión múltiple e insistente y se daba como objeto lo inconfesable-confesado” (Foucault 2002:81), sin embargo, como Foucault nos muestra en Obrar mal, decir la verdad, la confesión institucionalizada, regulada por el cristianismo, la medicina o lo jurídico, tiene una historia, un devenir. Sin embargo, lo significativo a nuestro juicio, radica, nuevamente, en el vínculo existente entre la confesión o el decir veraz, con el poder ejercido sobre quien obra mal o sobre quién debe confesar lo inconfesable en escenarios normalizados de coacción, como técnica de poder desplegados para aquello.

Hemos producido, parafraseando a Foucault, una sociedad eminentemente confesante, en nuestras relaciones personales, en la medicina... se confiesan crímenes, pecados, infidelidades, se dice quién eres o fuiste. La verdad presente en un doble juego, la verdad debe ser conocida por un soberano, pues, “¿pueden condenar a muerte a alguien que no conocen?” (Foucault 2014:246); y por otro, la verdad sobre sí mismo, se conjugan en razón del gobierno de las alma, de la conciencia... "El sujeto que practica el examen sobre sí mismo no es pues la sede de procesos más o menos oscuros que haya que descifrar y exponer a la luz del día. Aquí, el sujeto no es, en el fondo, sino el punto de cruce entre reglas de conductas que hay que recordar y el punto de partida de acciones futuras que deberán o deberían ajustarse a ese código. El sujeto se sitúa en el punto de cruce del código y las acciones, y su acto de examen de conciencia se sitúa exactamente allí.” (Foucault 2014:115) 


\section{Bibliografía}

Foucault, M. (2014), Obrar mal, decir la verdad. La función de la confesión en la justicia. Curso de Lovaina. Siglo XXI Editores, Buenos Aires.

Ídem (2010), El coraje de la verdad. El gobierno de sí y de los otros II. Curso en el Collège de France. Fondo de Cultura Económica, Buenos Aires.

Ídem (2009), El gobierno de sí y de los otros. Curso en el Collège de France. Fondo de Cultura Económica, Buenos Aires.

Ídem (2002), Historia de la sexualidad. 1.- La voluntad de saber. Siglo XXI Editores, México D.F.

Ídem (2000), Vigilar y castigar. El nacimiento de la prisión. Siglo XXI Editores, México D.F.

Ídem (1997), La arqueología del saber. Siglo XXI Editores, México D.F. 